\title{
Link between Periodontal Disease and Coronary Artery Disease: Bangladesh Perspective
}

\author{
A K M M Islam ${ }^{1}$, M M Rahman ${ }^{2}$, M Ullah ${ }^{3}$, L Yeasmin 4 \\ ${ }^{1}$ Department of Cardiology, Jessore Medical College, Jessore, ${ }^{2}$ Department of Prosthodontics, \\ Bangabandhu Sheikh Mujib Medical University, Dhaka, ${ }^{3}$ Department of Cardiology, National \\ Institute of Cardiovascular Diseases, Dhaka, ${ }^{4}$ Department of Prosthodontics, Bangabandhu \\ Sheikh Mujib Medical University, Dhaka.
}

\begin{abstract}
Keywords: Coronary Artery

Diseases, Periodontal Disease.

Abstract:

Coronary artery disease $(C A D)$ is an increasingly important medical and public healthproblem, and is the leading cause of mortality in Bangladesh. Besides conventional risk factors and ethnicity, a number of emerging risk factors may explain the undue prevalence of $C A D$ in this population. Periodontal disease $(P D)$ is one of them, with prevalence of approximately $50 \%$. As with many other diseases, PD is associated with CAD, and the association is independent of conventional risk factors. Low socioeconomic condition, illiteracy and ignorance, metabolic syndrome, nutritional deficiencies including hypovitaminosis $D$ presumably contribute to the prevalence of $P D$ in Bangladesh. In fact, $P D$ and CAD share some cardiometabolic risk factors including diabetes mellitus, obesity and metabolic syndrome. Future research will hopefully explore different aspects of both public health problems, namely, PD and CAD in the country. The information gathered thereby, will help formulate policy to promote good oral health and tackle the deadly epidemic of CAD more efficiently.
\end{abstract}

(Cardiovasc. j. 2014; 7(1): 44-54)

\section{Introduction:}

Coronary artery disease (CAD) is an important medical and public health issue because it is common and leading cause of death throughout the world. Bangladesh has been experiencing epidemiological transition from communicable disease to non-communicable disease (NCD). The overall mortality rate has decreased significantly over the couple of decades. But deaths due to chronic diseases, specially the 'fatal four' i.e. cardiovascular disease, cancer, chronic respiratory disease and diabetes, are increasing in an alarming rate. ${ }^{1} \mathrm{CAD}$ is an important contributor to one of the four i.e. cardiovascular disease. The unduly high prevalence of CAD in Bangladesh is not fully explained; besides epidemiological transition, environmental contaminants and genetic or metabolic makeup, a number of recently known lifestyle related factors may play important role in the aetiopathogenesis of CAD in this population. ${ }^{2}$ Periodontal disease (PD) may be one of them. However, the nature of interaction between PD and CAD has not been studied in the context of Bangladesh.

\section{Rationality of the Review}

Data related to CAD and PD in Bangladesh is often insufficient, suffers from statistical flaws and is not readily available. Many articles were published in national, non-indexed journals which are not available online and difficult to procure. Recognizing these limitations, the present review has been planned to compile the available data on this important public health issue. This review will hopefully encourage future research and act as a source of information.

\section{Methods:}

Data have been collected from the articles available from MEDLINE and BanglaJOL supported by the International Network for the Availability of Scientific Publications (INASP) up to the year 2014. Besides this, national journals which are not available online but recognized by the Bangladesh Medical and Dental Council have also been considered. 


\section{What is Periodontal disease?}

PDs comprise a continuum of conditions involving inflammation of gingival tissues in response to dental plaque accumulation, and may range from milder gingivitis to more advanced periodontitis. There may ("periodontitis") or may not ("gingivitis") be substantial inflammatory destruction of the supporting tissues, including gingival tissue, periodontal ligament, and alveolar bone. ${ }^{3}$ Gingivitis is a reversible inflammatory reaction of the dento-gingival tissues to bacterial plaque accumulation which resolves soon after the dental bacterial biofilm is disrupted. ${ }^{4}$ Periodontitis, in contrast, is a chronic inflammatory reactionof the same compartment involving not only superficial gingival tissues but also periodontal ligament and the alveolar bone. In its earlier stage, it is rather symptomless, presenting with gingival bleeding and swelling. But in more advanced stage of periodontitis, the inflammation extends deeper and deeper causing progressive destruction of the dental supporting tissues, gingival recession, drifting of teeth, mobility, suppuration, and eventually tooth exfoliation. ${ }^{5}$ (Figure 1)

Periodontitis is a chronic 'infectious/ inflammatory' disease of multifactorial aetiology; interplay between environmental and genetic factors play varying role in an individual patient. ${ }^{3}$ Bacterial infection, host inflammatory response and some predisposing factors are important in the aetiopathogenesis of periodontitis. Anaerobic bacteria like Porphyromonasgingivalis, Tannerella forsythia, Treponemadenticola, and Selenomonasnoxia, as well as, like Campylobacter rectus, Aggregatibacter (formerly Actinobacillus) actinomycetemcomitans, and Prevotellaintermedia, and spirochetes accumulate and organize in the dental biofilm to initiate the disease process, this is followed by activation of host's cell-mediated immuneresponse. ${ }^{6-12}$ Activated leucocytes in the gingival tissues generate disproportionate amounts of inflammatory mediators including cytokines-chemokines and matrix metalloproteinases (e.g. collagenase) promoting soft and hard tissue destruction. ${ }^{13}$

Figure 1. Periodontal anatomy in healthand disease. A tooth with anatomy in health (left side) and with periodontal disease (right side). The increased depth of gingival sulcus caused by loss ofthe gingival attachment to create a periodontal pocket; the loss of alveolar bone due to the inflammatory response from plaque and calculus.

Besides specific bacterial pathogens, poor oral hygiene, cigarette smoking, diabetes mellitus, osteoporosis, rheumatoid arthritis, obesity, metabolic syndrome, high sugary diet, ethnicity and psychological factors like stress are the known risk factors for PD. ${ }^{14-17}$ In addition, ignorance and illiteracy, low socioeconomic condition, smokeless tobacco consumption, and hypovitaminosis D may contribute to PD. PD and CAD share some prevalent risk factors which could confound a relationship between them. Such risk factors include: increasing age, smoking, alcohol abuse, race/ethnicity, education and socioeconomic status, male sex, diabetes mellitus, obesity, metabolic syndrome and some genetic polymorphisms. ${ }^{18-21}$

Diagnosis of PD is based on clinical, as well as, radiographic parameters; clinical findings include: gingival bleeding; halitosis (fetor oris); inflamed, tender gingiva; bleeding on probing; deep or deepening periodontal pockets while using a calibrated probe; mobility, shifting and spacing of the teeth. ${ }^{22}$ Periodontitis cannot be diagnosed by inspection alone, however, and requires specific diagnostic tests (periodontal probing and, sometimes, radiographs). ${ }^{23}$ For the purpose of epidemiological studies, 3 clinical parameters are typically recorded to assess the prevalence of PD: (1) Bleeding on probing, (2) pocket depth, and (3) clinical attachment level, which reflects the amount of periodontal tissue loss. ${ }^{3}$ Other markers of periodontitis include detection of subgingival microbial colonization by selected periodontal organisms ${ }^{24-27}$ and evaluation of serum IgG or IgA antibodies to selected periodontal bacteria ${ }^{28-35}$.

\section{Epidemiology of CAD}

South Asians are unduly prone to develop CAD. ${ }^{36}$ Most notable features of CAD in this population are the extreme prematurity and severity; 2 to 4 -fold higher prevalence, incidence, hospitalization and mortality; 5 to 10 years earlier onset of first myocardial infarction and 5 
to 10 -fold higher rates of myocardial infarction and death before the age of 40 years. ${ }^{36}$ The exact prevalence of CAD in Bangladesh is not known. Only a limited number of small-scale epidemiological studies are available. The reported values indication the prevalence of CAD include $0.33 \%$ in general population in $1976,{ }^{37}$ between $1.85 \%$ and $3.4 \%$ in rural ${ }^{38,39}$ and $19.6 \%$ in urban working professionals. ${ }^{40,41}$ Despite marked disparity in values, there seems to be a rising prevalence of CAD in Bangladesh. ${ }^{2,42}$

\section{Epidemiology of Periodontal disease}

Periodontitis is the most common chronic inflammatory disease seen in humans, affecting $20-50 \%$ of the population worldwide. ${ }^{43,44}$ However, severe periodontitis is relatively less common, may be less than $10 \%$ in general population. ${ }^{45-48}$ The exact prevalence of PD in Bangladesh is not known. Despite lack of adequate data, however, poor dental hygiene is common ${ }^{49}$ and periodontitis seems to be prevalent in in the country, especially in the adults and the economically weak population. ${ }^{50}$ The prevalence in Bangladesh has been found to be 18.5 to $42 \% .{ }^{49-52} \mathrm{~A}$ recent hospital-based study among the elderly diabetic population attending the Outpatient Department of BIRDEM Hospital revealed very high prevalence of dental caries e.g. $97 \%$, while missing or filled teeth were found in $96 \%$ of the study subjects. ${ }^{53}$ Among the rural school children between 5 to 15 years, the prevalence of dental caries, plaque, gingival bleeding and bleeding on probing was $69.6 \%$, $91.6 \%, 66.8 \%$ and $64 \%$ respectively. ${ }^{54}$

\section{The Link between PD and CAD}

Periodontitis has been found to be associated with a number of systemic diseases and conditions, including stroke, ${ }^{55}$ peripheral arterial disease, ${ }^{56}$ type 2 diabetes, ${ }^{57}$ rheumatoid arthritis, ${ }^{58}$ chronic kidney disease, ${ }^{59}$ and chronic obstructive pulmonary disease, ${ }^{60}$ Alzheimer's disease, ${ }^{61}$ cancers, ${ }^{62}$ anaemia,${ }^{63}$ and low-birth weight baby. ${ }^{64-65}$ Currently, however, there is a lack of consensus among experts on the nature of these associations and confusion among health care providers and the public on how to interpret this rapidly growing body of science. ${ }^{66}$

The relationship between $\mathrm{PD}$ and $\mathrm{CAD}$ is predominantly epidemiological based on cross- sectional and longitudinal studies, and their meta-analysis. The association between the two public health problems is independent of traditional cardiovascular risk factors. ${ }^{43}$ However; epidemiological studies can only suggest association, no causal relationship. Proving a causal link between PD and CAD will require large randomized controlled trials in which individuals are randomized to treatment vs. usual care of PD and followed carefully for CAD events. Such studies are lacking to date; and carrying out randomized control trials in this subject may be of ethical issue, because PD has already been found to have deleterious effect on human health, and depriving a study group of standard treatment of PD may be irrational.

Surrogate variables like C-reactive protein, antibodies against oral bacteria, endothelial function assessed by flow-mediated dilatation of brachial artery, have been used as outcome variables in the studies relating $\mathrm{PD}$ and $\mathrm{CAD}$; positive link has been found between the surrogate variables, $\mathrm{PD}$ and $\mathrm{CAD}$, and beneficial effects of treating PD on these surrogate variables have also been documented. ${ }^{67-69}$

Periodontal treatment resulted in consistent and progressive reductions in systemic inflammation and biomarkers of atherosclerosis. However, no studies have used hard outcomes such as primary or secondary cardiovascular events. Also, there are no studies on the effects of periodontal treatment on primary prevention of atherosclerosis, and only one feasibility trial is available to date on secondary prevention. ${ }^{43}$ The existing secondary prevention trial is the PAVE (Periodontitis and Vascular Events) study, a multicenter study involving subjects with established $\mathrm{CAD}$ and PD. These patients were randomized to receive either non-surgical periodontal therapy (experimental group) or basic oral primary care (control group). There were increased, but non-significant adverse cardiovascular events in the primary care (control) (6.6 vs. 3.3\%) group. ${ }^{70-71}$ Also, maintaining and promoting oral health has been found to be cost-effective. ${ }^{72-73}$

Traditionally, oral health and periodontal disease was neglected and left to the domain of dentists. However, in the recent years, it has become a 
matter of a growing tide of interest, swelled by a burgeoning literature, specially because of the possible link between PD and a number of chronic diseases. ${ }^{74}$

\section{Risk Factors for PD in Bangladesh}

Besides the well-known risk factors, ignorance and illiteracy, low socioeconomic condition, smokeless tobacco consumption, malnutrition and hypovitaminosis D may contribute to the prevalence PD in Bangladesh.

\section{Poor dental hygiene}

Dental hygiene appears to be a neglected subject, and poor dental hygiene is common in Bangladesh, ${ }^{49}$ specially in the adults and the economically weak population. ${ }^{50,52}$ Most of the people do not follow the basic rules of dental health. Regular brushing and flossing are not practiced methodically, scaling is done infrequently. Unsafe materials like wood coal, wood ash, and traditional tooth powder, even sand are used by people, specially those of lowsocioeconomic condition in urban slums and rural areas. These factors may compromise oral hygiene and predispose to PD. A study among 1200 school students aged 10-15 years in Dhaka city revealed that $69.2 \%$ respondents brushed their teeth regularly, $69.2 \%$ brushed once a day, $27.5 \%$ twice and only $3.3 \%$ more than twice a day; $92.5 \%$ used toothbrush and $83.3 \%$ used tooth paste. ${ }^{75}$ Contrary to the urban setting, tooth brush users were only $33.2 \%$ among the rural school children in another study involving 250 school children. ${ }^{54}$ Among the elderly patients attending the Outpatient Department of BIRDEM Hospital, Dhaka, daily tooth cleaning was practiced by $90 \%$; tooth brush users were $79 \%$, tooth paste users $85 \%$, dental floss users $44 \%$, brushing time of 1-3 minutes was followed by $49 \%$, and $82 \%$ of those taking snacks between meals did not clean the mouth after snacks. ${ }^{53}$ However, this is an urban hospital mainly catering to the relatively well-to-do people, hence may not represent the majority.

\section{Ignorance and illiteracy}

PD has a reciprocal relationship with educational level; ${ }^{14}$ the higher the educational level, the lower the periodontal diseases. Despite recent advances, the adult literacy rate in Bangladesh remains low e.g. $57.7 \% .{ }^{76}$ The illiterate people are unaware of the concept of healthy lifestyle, including importance of dental health. Even the literate people are relatively less motivated about oral hygiene. The physicians often leave this issue to the dentists. In a study involving the urban school children in Dhaka city, ${ }^{75} 92.5 \%$ understood the importance of taking care of oral cavity, $76.7 \%$ agreed that regular brushing would prevent tooth decay, $67.5 \%$ knew that sweet food caused harm to teeth and $50.0 \%$ thought that soft drinks would have the same effects on teeth. Again, this was an urban school-based study mainly involving the well-to-do children, and hence may not be representative of the general people of Bangladesh.

\section{Low socioeconomic condition}

The possible relationship between periodontal disease and socioeconomic status was found in several studies. ${ }^{77-81}$ In Bangladesh, a large number of the people still live in low socioeconomic condition; the country's gross national income per capita was only USD $2,030,3.6 \%$ of GDP was for total health expenditure, and the per capita health expenditure was only USD 68 in $2012 .{ }^{82}$ This low-income population in general is more prone to malnutrition and infection, and becomes victim to poor oral hygiene, including $\mathrm{PD}$. In a recent study in Dhaka city, ${ }^{75} 69.2 \%$ of the school children went to dentist on requirement basis and only 8.3\% underwent regular dental checkup. Again, this is an urban school-based study mainly involving the well-to-do children, and hence may not reflect the real scenario of Bangladesh.

\section{Smoking and smokeless tobacco use}

Besides its major role in CAD, smoking is a strong risk factor for PDs; down-regulation of anti-inflammatory factors and up-regulation of pro-inflammatory cytokines may be the explanation. ${ }^{83,84} \mathrm{Also}$, smoking cessation has beneficial effect on occurrence and healing of PD. ${ }^{85-86}$ Besides cigarette smoking, consumption of smokeless tobacco e.g. betel quid chewing with or without tobacco leaf is a recognized risk factor for PD and its severity. ${ }^{87,88}$ Tobacco consumption is quite common in Bangladesh: prevalence is $51.0 \%$ for any form, $26.2 \%$ for smoking and $31.7 \%$ for smokeless tobacco. ${ }^{89}$ In a recently 
published study, betel quid chewing was found in $33.2 \%$ of rural population..$^{90}$ Bangladesh is one of top 10 countries that make up two-thirds of the world population of smokers. ${ }^{91}$ Such a high prevalence of smoking and smokeless tobacco consumption presumably play important role in the prevalence of PD in Bangladesh.

\section{Diabetes Mellitus}

Diabetes mellitus has been found to be associated with occurrence and severity of PD. ${ }^{92-93}$ Exact prevalence of DM in Bangladesh is not known. According to the (NCD) Risk Factor Survey $2010,{ }^{89}$ prevalence of self-reported or documented DM is $3.9 \%$ (men $4.3 \%$ and women $3.6 \%)$. The prevalence of DM in rural populationwas $7.2 \%$ in a recent study. ${ }^{94}$ Like in all other developed and developing countries, prevalence and incidence of type $2 \mathrm{DM}$ is increasing in Bangladesh. In 2010, the International Diabetes Federation (IDF) estimated that 5.7 million (6.1\%) and 6.7 million (7.1\%) of people living in Bangladesh is suffering from DM and impaired glucose tolerance(IGT) respectively; by 2030, that number of diabetic population is expected to rise to 11.1 million. ${ }^{95}$ High prevalence of diabetes may contribute to the burden of PD in Bangladesh.

\section{Obesity}

A significant association exists between obesity and periodontitis. ${ }^{96-7}$ Bangladesh is going through an adult nutritional transition with increases in pre-obesity and obesity particularly in urban areas. ${ }^{98}$ In general, $21.5 \%$ adults (male $21 \%$, female $22 \%$ ) have body-mass index (BMI) e" 25 $\mathrm{kg} / \mathrm{m}^{2}$; increased waist circumference is alarming especially in women (33.7\%). ${ }^{89}$ However, the significance of obesity and its contribution to PD has not been studied in Bangladesh.

\section{Metabolic syndrome}

Recently, a positive link has been found between the metabolic syndrome and PD. ${ }^{99} \mathrm{As}$ a result of socioeconomic transition, lifestyle, as well as, the dietary pattern is changing in Bangladesh. Logically, metabolic syndrome is becoming an important health issue in this country, as well. The prevalence of metabolic syndrome has been found to be $20.7 \%, 11.2 \%$ and $8.6 \%$ following modified Adult Treatment Panel III,
International Diabetes Federation and World Health Organization definitions, respectively. ${ }^{100}$ In a recently published study, $19.5 \%$ of older persons in rural Bangladesh - 20.8\% women, and $18.0 \%$ men - had metabolic syndrome. ${ }^{101}$ Prevalence of metabolic syndrome presumably contributes to both PD and CAD in Bangladesh.

\section{Osteoporosis}

There may be a relationship between osteopenia, oral bone loss, and PD, ${ }^{102-104}$ and osteopenia does play a role in the expression of PD. ${ }^{14}$ The exact prevalence of osteoporosis in Bangladesh is not known. Limited data indicate that Bangladeshi women may have lower bone mineral density in comparison to that in the western population. ${ }^{105}$ Osteopenia and osteoporosis seems to be a common problem in Bangladeshi population; in a recent study involving women, 43.6 and 5.5\% of $16-45$ year old women, and 40.7 and $41.8 \%$ of 46-65 year old women had osteopenia and osteoporosis, respectively. ${ }^{106} \mathrm{High}$ prevalence of osteoporosis may contribute to PD.

\section{Hypovitaminosis D}

Vitamin D deficiency predisposes to PD and tooth loss, and vitamin D supplementation may have protective and beneficial effect on dental health. ${ }^{107-110}$ Few studies have been carried out to determine the prevalence of hypovitaminosis $\mathrm{D}$ in Bangladesh. There may be high prevalence of vitamin D deficiency in the population; $78 \%$ of university students and $83 \%$ of veiled women had hypovitaminosis D. ${ }^{111-112}$ Further research is needed to find out the association, if any, between vitamin $\mathrm{D}$ deficiency and $\mathrm{PD}$ in Bangladesh.

\section{Malnutrition}

In the recent decade, Bangladesh has made spectacular health achievement despite economic poverty, which has been termed 'Bangladesh paradox'. The Bangladesh paradox shows the net outcome of successful direct health action in both positive and negative social determinants of health-i.e., positives such as women's empowerment, widespread education, and mitigation of the effect of natural disasters; and negatives such as low gross domestic product, pervasive poverty, and the persistence of income inequality. ${ }^{113}$ However, despite epidemiological 
and adult nutritional transition, a high percentage of the population of Bangladesh remains undernourished. ${ }^{98}$ The prevalence of underweight (weight-for-age z-score <-2) among children aged $<5$ years is still high $(41 \%)$, nearly one-third of women are undernourished with body mass index of $<18.5 \mathrm{~kg} / \mathrm{m}^{2}$, and the prevalence of anaemia among young infants, adolescent girls, and pregnant women is still at unacceptable levels. ${ }^{114}$ In 1995/96, prevalence of anaemia was $74 \%$ in general, $64 \%$ in urban areas and $77 \%$ in rural areas. Iron deficiency may be an important cause of anaemia in the Bangladeshi population. ${ }^{115}$ In a recent study in Noakhali region, $55.3 \%$ university students were found anaemic, of whom $36.7 \%$ were male, and $63.3 \%$ were female. ${ }^{116}$ Such a high prevalence of under-nutrition and accompanying anaemia, osteoporosis and hypovitaminosis may presumably predispose to PD.

\section{Psychological factors}

In the recent years, a positive relationship between psychological factors including stress and periodontal disease has been described.117118 Mental illnesses are important but underrecognized public health problems in Bangladesh; awareness about mental illness and acceptance of treatment are very low due to social stigma and superstition. ${ }^{119}$ Nation-wide survey on mental health in Bangladesh in 2003-2005 found the prevalence of mental disorders $16.05 \%$ in adult population. ${ }^{120}$ In other studies, the prevalence of mental disorders was $28 \%$ in urban areas ${ }^{121}$ and $16.5 \%$ in rural areas. ${ }^{122}$ No definite studies have been carried out in Bangladesh to find out the significance of psychosocial stress in the context of PD in this population.

\section{Future Directions}

Data related to different aspects of periodontal disease as well as of IHD in Bangladesh are inadequate. Large, preferably nationwide epidemiological and clinical studies should be carried out to gain reliable information on these important public health issues. Mass awareness should be created regarding health impact of bad oral hygiene, and health benefit of promoting good oral hygiene. Physicians should be trained of basics of periodontal disease. Oral hygiene should not be left exclusively to the jurisdiction of the dentists; rather the physicians and dentists should work hand in hand. Dentists should pay attention to the risk factor management in relation to PD and IHD for smoking cessation, reduction of sugar consumption, and weight control while dealing with individual patient. ${ }^{123}$ Periodontal disease prevention should be integrated with primary health care. Oral health promotion should be part of the national media strategyand the health education curriculum. The public health approach should target population-wide life style intervention, screening for components of metabolic syndrome including DM and obesity.Healthy lifestyles including consumption of heart-healthy diets, avoidance to smoking and smokeless tobacco, moderation of sugary diets, should be promoted. All sorts of tobacco consumption should be discouraged, and should be dealt with rigorously. Necessary legislative and administrative steps should be taken in this regard. Special attention should be given to stop malnutrition and undernutrition. Public awareness should be created to avoid childhood obesity. If indicated by further research, vitamin D deficiency should be avoided by fortification of food. Intensive research, may be in collaboration with international organizations, should be undertaken to explore the still-unidentified risk factors unique to this nation which are responsible for the prevalence of PD and IHD in Bangladesh.

\section{Conclusion}

Periodontal disease is associated with IHD independent of traditional cardiovascular risk factors. Treatment and prevention of PD can help to prevent IHD, and probably a number of other diseases. Management of PD and promotion of oral health may be feasible and cost-effective. Both PD and IHD appear to be highly prevalent in Bangladesh, so, having great public health importance. Future research will hopefully determine the different aspects of PD and IHD in Bangladesh, including the link between the two. The information available thereby, would help to formulate national policy to combat these important public health issues more efficiently in future.

Conflict of Interest - None. 


\section{References:}

1. Strategic plan for surveillance and prevention of noncommunicable diseases in Bangladesh 2011-2015. Directorate General of Health Services, Ministry of Health and Family Welfare. August 2011, Dhaka.

2. Islam AK, Majumder AA. Coronary artery disease in Bangladesh: a review. Indian Heart J. 2013 JulAug;65(4):424-35. doi: 10.1016/j.ihj.2013.06.004. Review.

3. Lockhart PB, Bolger AF, Papapanou PN, et al, on behalf of the American Heart Association Rheumatic Fever, Endocarditis, and Kawasaki Disease Committee of the Council on Cardiovascular Disease in the Young, Council on Epidemiology and Prevention, Council on Peripheral Vascular Disease, and Council on Clinical Cardiology. Periodontal disease and atherosclerotic vascular disease: does the evidence support an independent association?: a scientific statement from the American Heart Association. Circulation 2012;125:2520-2544.

4. Loe H, Theilade E, Jensen SB. Experimental gingivitis in man. J Periodontol 1965;36:177-187.

5. Williams RC. Periodontal disease. $N$ Engl J Med 1990;322:373-382.

6. Socransky SS, Haffajee AD. Microbiology of periodontal disease. In: Lindhe J, Karring T, Lang NP, eds. Clinical Periodontology and Implant Dentistry. Oxford, UK: Blackwell Munksgaard; 2003:chap 4.

7. Paster BJ, Boches SK, Galvin JL, et al. Bacterial diversity in human subgingival plaque. J Bacteriol 2001;183:37703783.

8. Haffajee AD, Cugini MA, Tanner A, et al. Subgingival microbiota in healthy, well-maintained elder and periodontitis subjects. J Clin Periodontol 1998; 25:346353.

9. Tanner A, Maiden MF, Macuch PJ, Murray LL, Kent RL Jr. Microbiota of health, gingivitis, and initial periodontitis. J Clin Periodontol 1998;25:85-98.

10. Choi BK, Paster BJ, Dewhirst FE, Go" bel UB. Diversity of cultivable and uncultivable oral spirochetes from a patient with severe destructive periodontitis. Infect Immun. 1994;62:1889-1895.

11. Moore LV, Moore WE, Cato EP, et al. Bacteriology of human gingivitis. J Dent Res 1987;66:989-995.

12. Loesche WJ, Gusberti F, Mettraux G, Higgins T, Syed S. Relationship between oxygen tension and subgingival bacterial flora in untreated human periodontal pockets. Infect Immun 1983;42:659-667.

13. Loe $\mathrm{H}$. Principles of aetiology and pathogenesis governing the treatment of periodontal disease. Int Dent $J$ 1983;33:119-126.

14. AlJehani YA.Risk factors of periodontal disease: review of the literature. Int J Dent 2014;2014:182513. doi: 10.1155/ $2014 / 182513$.

15. Sanz M, D'Aiuto F, Deanfield J, and Fernandez-Avile's F. European workshop in periodontal health and cardiovascular disease-scientific evidence on the association between periodontal and cardiovascular diseases: a review of the literature. European Heart Journal Supplements 2010; 12 (Supplement B), B3-B12. doi:10.1093/eurheartj/suq003.

16. Borrell LN, Papapanou PN. Analytical epidemiology of periodontitis. J Clin Periodontol 2005;32(suppl 6):132-158.

17. Consensus report: periodontal diseases: pathogenesis and microbial factors. Ann Periodontol 1996;1:926-932.

18. Vedin O, Hagström E, Gallup D, et al. Periodontal disease in patients with chronic coronary heart disease: Prevalence and association with cardiovascular risk factors. Eur $J$ Prev Cardiol. 2014 Apr 10. [Epub ahead of print].

19. Kornman KS, Duff GW. Candidate genes as potential links between periodontal and cardiovascular diseases. Ann Periodontol 2001;6:48-57.

20. Hujoel PP, Drangsholt M, Spiekerman C, DeRouen TA. Periodontal disease and coronary heart disease risk. JAMA 2000; 284:1406-1410.

21. Peacock ME, Carson RE. Frequency of self-reported medical conditions in periodontal patients. J Periodontol 1995;66:1004-1007.

22. Hoexter DL. Periodontal treatment for the general practitioner: Systemic management of chronic periodontitis. (Spectrum JA04 8/17/04 1:18 PM Page 34.

23. Coventry J, Griffiths G, Scully C, Tonetti M. ABC of oral health: Periodontal disease. BMJ 2000;321:36-39.

24. Nonnenmacher C, Stelzel M, Susin C, et al. Periodontal microbiota in patients with coronary artery disease measured by real-time polymerase chain reaction: a casecontrol study. J Periodontol 2007;78:1724-1730.

25. Spahr A, Klein E, Khuseyinova N, et al. Periodontal infections and coronary heart disease: role of periodontal bacteria and importance of total pathogen burden in the Coronary Event and Periodontal Disease (CORODONT) study. Arch Intern Med 2006;166:554-559.

26. Renvert S, Pettersson T, Ohlsson O, Persson GR. Bacterial profile and burden of periodontal infection in subjects with a diagnosis of acute coronary syndrome. J Periodontol 2006; $77: 1110-1119$

27. Desvarieux M, Demmer RT, Rundek T, et al. Periodontal microbiota and carotid intima-media thickness: the Oral Infections and Vascular Disease Epidemiology Study (INVEST). Circulation 2005; 111:576-582.

28. Lund Håheim L, Olsen I, Nafstad P, Schwarze P, Rønningen KS. Antibody levels to single bacteria or in combination evaluated against myocardial infarction. $J$ Clin Periodontol 2008;35:473-478.

29. Pussinen PJ, Paju S, Ma“ntyla“ P, Sorsa T. Serum microbial and host-derived markers of periodontal diseases: a review. Curr Med Chem. 2007;14:2402-2412.

30. Pussinen PJ, Jousilahti P, Alfthan G, Palosuo T, Asikainen $\mathrm{S}$, Salomaa V. Antibodies to periodontal pathogens are associated with coronary heart disease. Arterioscler Thromb Vasc Biol 2003;23:1250-1254. 
31. Pussinen PJ, Alfthan G, Tuomilehto J, Asikainen S, Jousilahti P. High serum antibody levels to Porphyromonas gingivalis predict myocardial infarction. Eur J Cardiovasc Prev Rehabil 2004;11:408-411.

32. Pussinen PJ, Alfthan G, Rissanen H, Reunanen A, Asikainen S, Knekt P. Antibodies to periodontal pathogens and stroke risk. Stroke 2004;35: 2020-2023.

33. Beck JD, Eke P, Heiss G, et al. Periodontal disease and coronary heart disease: a reappraisal of the exposure. Circulation 2005;112:19-24.

34. Beck JD, Eke P, Lin D, et al. Associations between IgG antibody to oral organismsand carotid intima-medial thickness in community-dwelling adults. Atherosclerosis 2005; 183:342-348.

35. Pussinen PJ, Nyyssonen K, Alfthan G, Salonen R, Laukkanen JA, Salonen JT. Serum antibody levels to Actino bacillus actinomycetem comitans predict the risk for coronary heart disease. Arterioscler Thromb Vasc Biol 2005;25: 833-838..

36. Enas EA, Senthilkumar A. Coronary artery disease in Asian Indians: An update and review. Int J Cardiol 2001;1(2).

37. Malik A. Congenital and acquired heart diseases (a survey of 7062 persons). Bangladesh Med Res Council Bull 1976;II: 115-119.

38. Sayeed MA, Mahtab H, Sayeed S, et al. Prevalence and risk factors of coronary heart disease in a rural population of Bangladesh. Ibrahim Medical College Journal 2010; 4(2): 37-43.

39. Zaman MM, Ahmed J, Choudhury SR, et al. Prevalence of ischemic heart disease in a rural population of Bangladesh. Indian Heart J 2007 May-Jun;59(3):239-241.

40. Ahsan S, Haque KMHS, Salman M, et al. Detection of ischaemic heart disease with risk factors in different categories of employees of University Grants Commission. University Heart Journal 2009, 5:20-23.

41. Saquib N, Saquib J, Ahmed T, et al. Cardiovascular diseases and Type 2 diabetes in Bangladesh: A systematic review and meta-analysis of studies between 1995 and 2010. BMC Public Health 2012 Jun 13;12:434.doi: 10.1186/ 1471-2458-12-434.

42. AhsanKarar Z, Alam N, Kim Streatfield P. Epidemiological transition in rural Bangladesh, 1986-2006. Glob Health Action. 2009;2.

43. Chapple IL. Time to take periodontitis seriously. The benefits of treatment are likely to exceed the costs. BMJ. 2014 Apr 10;348:g2645. doi: 10.1136/bmj.g2645.

44. White DA, Tsakos G, Pitts NB, et al. Adult Dental Health Survey 2009: common oral health conditions and their impact on the population. Br Dent J. 2012;213:567-572.

45. Albandar JM, Rams TE. Global epidemiology of periodontal diseases: an overview. Periodontol 2000 2002;29:7-10.

46. Eke PI, Genco RJ. CDC Periodontal Disease Surveillance Project: background, objectives, and progress report. $J$ Periodontol 2007;78 (Suppl. 7):1366-1371.
47. Hugoson A, Norderyd O. Has the prevalence of periodontitis changed during the last 30 years? J Clin Periodontol 2008 Sep;35(8 Suppl):338-345. doi: 10.1111/ j.1600-051X.2008.01279.x. Review.

48. Kinane D, Bouchard P. Periodontal diseases and health: Consensus Report of the Sixth European Workshop on Periodontology. J Clin Periodontol. 2008;35 (Suppl. 8):333337.

49. Van PalensteinHelderman WH, Joarder MA, Begum A. Prevalence and severity of periodontal diseases and dental caries in Bangladesh. Int Dent J 1996; 46(2):76-81.

50. Jacob PS. Periodontitis in India and Bangladesh. Need for a population based approach in epidemiological surveys. A literature review. Bangladesh Journal of Medical Science 2010;9(3):124-130.

51. Akhter R, Hassan NM, Aida J, et al. Risk indicators for tooth loss due to caries and periodontal disease in recipients of free dental treatment in an adult population in Bangladesh. Oral Health Prev Dent. 2008; 6(3):199-207.

52. Arvidson-Bufano UB, Holm AK. Dental health in urban and rural areas of central and western Bangladesh. Odontostomatol. Trop 1990;13(3):81-86.

53. Debnath S, Farzan MAS, Zerin I, Kabir MA, Hossain MS. Dental status and oral hygiene practice among the elderly people attending the Outpatient Department of BIRDEM Hospital, Dhaka. Bangladesh Journal of Dental Research \& Education 2012; 2(1):17-21.

54. Sarwar AFM, Kabir MH, Rahman AFMM, et al. Oral hygiene practice among the primary school children in selected rural areas of Bangladesh. Journal of Dhaka National Medical College \& Hospital 2011; 18 (01):43-48.

55. Lafon A, Pereira B, Dufour T, et al. Periodontal disease and stroke: a meta-analysis of cohort studies. Eur J Neurol. 2014 Apr 8. doi: 10.1111/ene.12415. [Epub ahead of print].

56. Soto-Barreras U, Olvera-Rubio JO, Loyola-Rodriguez JP, et al. Peripheral arterial disease associated with caries and periodontal disease. J Periodontol 2013 Apr;84(4):48694. doi: 10.1902/jop.2012.120051.

57. Chapple IL, Genco R; Working group 2 of joint EFP/AAP workshop.Diabetes and periodontal diseases: consensus report of the Joint EFP/AAP Workshop on Periodontitis and Systemic Diseases. J ClinPeriodontol. 2013 Apr;40Suppl 14:S106-12. doi: 10.1111/jcpe.12077.

58. DePablo P, Chapple ILC, Buckley CD, Dietrich T. Periodontitis and systemic rheumatic diseases. Nat Rev Rheumatol 2009;5:218-224.

59. Sharma P, Dietrich T, Sidhu A, et al. The periodontal health component of the Renal Impairment In Secondary Care (RIISC) cohort study: a description of the rationale, methodology and initial baseline results. $J$ ClinPeriodontol. 2014 Jul;41(7):653-61. doi: 10.1111/ jcpe.12263.

60. Zeng XT, Tu ML, Liu DY, Zheng D, Zhang J, Leng W. Periodontal disease and risk of chronic obstructive pulmonary disease: a meta-analysis of observational 
studies. PLoS One. 2012;7(10):e46508. doi: 10.1371/ journal.pone.0046508. Epub 2012 Oct 19.

61. Singhrao SK, Harding A, Simmons T, Robinson S, Kesavalu L, Crean S. Oral inflammation, tooth loss, risk factors, and association with progression of Alzheimer's disease. J Alzheimers Dis. 2014 Jun 19. [Epub ahead of print].

62. Zeng XT, Deng AP, Li C, Xia LY, Niu YM, Leng WD. Periodontal disease and risk of head and neck cancer: a meta-analysis of observational studies. PLoS One. 2013 Oct 23;8(10):e79017. doi: 10.1371/journal.pone.0079017. eCollection 2013.

63. Patel MD, Shakir QJ, Shetty A. Interrelationship between chronic periodontitis and anemia: A 6-month follow-up study. J Indian Soc Periodontol. 2014 Jan;18(1):19-25. doi: 10.4103/0972-124X.128194.

64. Jacob PS, Nath S. Periodontitis among poor rural Indian mothers increases the risk of low birth weight babies: a hospital-based case control study. J Periodontal Implant Sci. 2014 Apr;44(2):85-93. doi: 10.5051/jpis.2014.44.2.85.

65. Sitholimela CS, Shangase LS. The association between periodontitis and pre-term birth and/or low birth weight: a literature review. SADJ 2013 May;68(4):162-166.

66. Otomo-Corgel J, Pucher JJ, Rethman MP, Reynolds MA. State of the science: chronic periodontitis and systemic health. J Evid Based Dent Pract. 2012 Sep;12(3 Suppl):208. doi: 10.1016/S1532-3382(12)70006-4.

67. Paraskevas S, Huizinga JD, Loos BG. A systematic review and meta-analyses on C-reactive protein in relation to periodontitis. J Clin Periodontol. 2008;35:277-290.

68. Mustapha IZ, Debrey S, Oladubu M, Ugarte R. Markers of systemic bacterial exposure in periodontal disease and cardiovascular disease risk: a systematic review and metaanalysis. J Periodontol 2007;78:2289-2302.

69. Danesh J, Whincup P, Walker M, et al. Low grade inflammation and coronary heart disease: prospective study and updated meta-analyses. BMJ 2000;321:199-204.

70. Beck JD, Couper DJ, Falkner KL, et al. The Periodontitis and Vascular Events (PAVE) Pilot Study: adverse events. J Periodontol. 2008;79:2089-2100.

71. Couper DJ, Beck JD, Falkner KL, et al. The Periodontitis and Vascular Events (PAVE) Pilot Study: recruitment, retention, and community care controls. J Periodontol 2008;79:80-89.

72. Cigna Health and Life Insurance Company. 2013. Improved health and lower medical costs: why good dental care is important.c2014. [cited 2014 Jun 30]. Available at:http://kb.previser.com/wp-content/uploads/2013/12/ Cigna-Possible-Medical-Savings-from-Improved-DentalCare.pdf.accessed30 Jun 2014.

73. PR Newswire Association LLC. New research continues to show medical cost savings and reduced hospitalizations possible with gum disease treatment. [homepage on the Internet] c2014. [cited 2014 Jun 30]. Available at:http:// insurancenewsnet.com/oarticle/2014/03/21/new-researchcontinues-to-show-medicalcost-savings-and-reducedhospitalizations-a-477675.html.
74. Davis M. Periodontal disease- another cardiovascular risk factor to consider? Br J Cardiol 2009;16:11-12.

75. Ahmed S, Solaiman F, Islam MR, Akhter SM, Nizami MZI, Khatun MA. Attitude on oral hygiene among the school going children in selected schools at Dhaka city. City Dental College Journal 2013;10(2):41-46.

76. UNICEF - Bangladesh - Statistics. [homepage on the Internet] c2014 [cited 2014 Jun 30]. Available at: http:// www.unicef.org/infobycountry/bangladesh_bangladesh_ statistics.html.

77. Gilbert GH. Racial and socioeconomic disparities in health from population-based research to practice-based research: the example of oral health. J Dent Educ 2005 Sep;69(9):1003-1014.

78. Susin C, Oppermann RV, Haugejorden O, Albandar JM. Tooth loss and associated risk indicators in an adult urban population from south Brazil. Acta Odontol Scand 2005 Apr;63(2):85-93.

79. Locker D, Leake JL. Periodontal attachment loss in independently living older adults in Ontario, Canada. $J$ Public Health Dent 1993 Winter;53(1):6-11.

80. Erde EL. Irrational and pregnant. Hastings Cent Rep 1992 May-Jun; 22(3):45.

81. Beck JD, Koch GG, Rozier RG, Tudor GE. Prevalence and risk indicators for periodontal attachment loss in a population of older community-dwelling blacks and whites. J Periodontol. 1990 Aug; 61(8):521-528.

82. World Health Organization | Bangladesh.[homepage on the Internet] c2014 [cited 2014 Jun 30]. Available at: http:/ /www.who.int/countries/bgd/en/.

83. César Neto JB, Rosa EF, Pannuti CM, Romito GA. Smoking and periodontal tissues: a review. Braz Oral Res 2012; 26Suppl 1:25-31. Review.

84. Underner M, Maes I, Urban T, Meurice JC. Effects of smoking on periodontal disease].[Article in French] Rev Mal Respir 2009 Dec;26(10):1057-1073.

85. Fiorini T, Musskopf ML, Oppermann RV, Susin C. Is there a positive effect of smoking cessation on periodontal health? A systematic review. J Periodontol 2014 Jan; 85(1):83-91. doi: 10.1902/jop.2013.130047..

86. Chambrone L. Smoking cessation may positively improve clinical periodontal parameters. J Evid Based Dent Pract. 2014 Jun;14(2):76-8. doi: 10.1016/j.jebdp.2014.04.014.

87. Javed F, Tenenbaum HC, Nogueira-Filho G, et al. Severity of periodontal disease in individuals chewing betel quid with and without tobacco. Am J Med Sci 2013 Oct;346(4):273-8. doi: 10.1097/MAJ.0b013e31827333fb.

88. Anand PS, Kamath KP, Bansal A, Dwivedi S, Anil S. Comparison of periodontal destruction patterns among patients with and without the habit of smokeless tobacco use-a retrospective study. J Periodontal Res 2013 Oct;48(5):623-31. doi: 10.1111/jre.12048.

89. World Health Organization. Bangladesh NCD risk factor survey 2010. World Health Organization: Country Office 
for Bangladesh. c2014 [cited 2014Jun30]. Available at: http://www.who.int/chp/steps/2010_STEPS_ Report_ Bangladesh.pdf.

90. Heck JE, Marcotte EL, Argos M, et al. Betel quid chewing in rural Bangladesh: prevalence, predictors and relationship to blood pressure. Int J Epidemiol 2011;1-10.

91. Hanifi SA, Mahmood SS, Bhuiya A. Smoking has declined but not for all: Findings from a study in a rural area of Bangladesh. Asia Pac J Public Health 2011 Sep;23(5):662671.

92. Al-Khabbaz AK. Type 2 diabetes mellitus and periodontal disease severity. Oral Health Prev Dent 2014;12(1):77-82. doi: 10.3290/j.ohpd.a31223.

93. Moodley A, Wood NH, Shangase SL. The relationship between periodontitis and diabetes: a brief review. SADJ $2013 \mathrm{Jul} ; 68(6): 260,262-264$.

94. Akhter A, Fatema K, Afroz A, et al. Prevalence of diabetes mellitus and its associated risk indicators in a rural Bangladeshi population. The Open Diabetes Journal 2011;4, 6-13.

95. Shaw JE, Sicree RA, Zimmet PZ. Diabetes atlas: Global estimates of the prevalence of diabetes for 2010 and 2030. Diabetes Res Clin Pract. 2010; 87: 4-14.

96. Moura-Grec PG, Marsicano JA, Carvalho CA, Sales-Peres SH. Obesity and periodontitis: systematic review and metaanalysis. Cien Saude Colet 2014 Jun;19(6):1763-1772.

97. Suresh S, Mahendra J. Multifactorial relationship of obesity and periodontal disease. J Clin Diagn Res 2014 Apr;8(4):ZE01-3. doi: 10.7860/JCDR/2014/7071.4227.

98. Mascie-Taylor N. Is Bangladesh going through an epidemiological and nutritional transition? Coll Antropol. 2012 Dec; 36(4):1155-1159.

99. Gurav AN. The association of periodontitis and metabolic syndrome. Dent Res J (Isfahan) 2014 Jan; 11(1):1-10.

100. Rahima MA, Khan AKA, Sayeed MA, et al. Metabolic syndrome in rural Bangladesh: Comparison of newly proposed IDF, modiued ATP III and WHO criteria and their agreements. Diabetes \& Metabolic Syndrome: Clinical Research \& Reviews 2007;1: 251-257.

101. Khanam MA, Qiu C, Lindeboom W, et al. The metabolic syndrome: Prevalence, associated factors, and impact on survival among older persons in rural Bangladesh. PLoS One. 2011;6(6):e20259. doi: 10.1371/journal.pone.0020259. Epub 2011 Jun 15.

102. Chang WP, Chang WC, Wu MS, et al. Population-based 5year follow-up study in Taiwan of osteoporosis and risk of periodontitis. J Periodontol 2014 Mar;85(3):e24-30. doi: 10.1902/jop.2013.130256.

103. Kim JW, Kong KA, Kim HY, et al. The association between bone mineral density and periodontitis in Korean adults (KNHANES 2008-2010). Oral Dis 2013 Aug 26. doi: 10.1111/odi.12179.

104. Vishwanath SB, Kumar V, Kumar S, Shashikumar P, Shashikumar Y, Patel PV. Correlation of periodontal status and bone mineral density in postmenopausal women: a digital radiographic and quantitative ultrasound study. Indian J Dent Res 2011 Mar-Apr;22(2):270-6. doi: 10.4103/ 0970-9290.84303.

105. Reza S, Rahman M, Hossain S, Afroz S. Bone mineral densities in normal Bangladeshi women. Iran J Radiat Res 2008; 6 (3): 157-160.

106. Begum RA, Ali L, Akter J, Takahashi O, Fukui T, Rahman M. Osteopenia and osteoporosis among 16-65 year old women attending outpatient clinics. J Community Health. 2014 Mar 6. [Epub ahead of print].

107. Zhan Y, Samietz S, Holtfreter B, et al. Prospective study of serum 25-hydroxy vitamin D and tooth loss. J Dent Res 2014 May 14;93(7):639-644.

108. Jimenez M, Giovannucci E, Krall Kaye E, Joshipura KJ, Dietrich T. Predicted vitamin D status and incidence of tooth loss and periodontitis. Public Health Nutr 2014 Apr;17(4):844-52.doi: 10.1017/S1368980013000177.

109. Millen AE, Hovey KM, LaMonte MJ, et al. Plasma 25hydroxyvitamin D concentrations and periodontal disease in postmenopausal women. J Periodontol 2013 Sep;84(9):1243-56. doi: 10.1902/jop.2012.120445.

110. Alshouibi EN, Kaye EK, Cabral HJ, Leone CW, Garcia RI. Vitamin D and periodontal health in older men. J Dent Res 2013 Aug;92(8):689-93. doi: 10.1177/0022034513495239.

111. Islam MZ, Akhtaruzzaman M, Lamberg-Allardt C. Hypovitaminosis D is common in both veiled and nonveiled Bangladeshi women. Asia Pac J Clin Nutr 2006;15(1):81-7.

112. Islam MZ, 112. Lamberg-Allardt C, Kärkkäinen M, et al. Vitamin D deficiency: A concern in premenopausal Bangladeshi women of two socio-economic groups in rural and urban region. Eur J Clin Nutr 2002;56(1):51-56.

113. Chowdhury AM, Bhuiya A, Chowdhury ME, Rasheed S, Hussain Z, Chen LC. The Bangladesh paradox: exceptional health achievement despite economic poverty.Lancet 2013 Nov 23;382(9906):1734-45. doi: 10.1016/S01406736(13)62148-0.

114. Ahmed T, Mahfuz M, Ireen S, et al. Nutrition of children and women in Bangladesh: trends and directions for the future. J Health Popul Nutr 2012 Mar;30(1):1-11.

115. Ahmed F. Anaemia in Bangladesh: a review of prevalence and aetiology. Public Health Nutr 2000 Dec;3(4):385-393.

116. Shill KB, Karmakar P, Kibria MG, et al. Prevalence of iron-deficiency anaemia among university students in Noakhali region, Bangladesh. J Health Popul Nutr 2014 Mar;32(1):103-110.

117. Goyal S, Gupta G, Thomas B, Bhat KM, Bhat GS. Stress and periodontal disease: The link and logic!! Ind Psychiatry J 2013 Jan; 22(1):4-11. doi: 10.4103/0972-6748.123585.

118. Peruzzo DC, Benatti BB, Ambrosano GM, et al. A systematic review of stress and psychological factors as possible risk factors for periodontal disease. J Periodontol 2007 Aug;78(8):1491-1504. Review. 
119. World Health Organization. Prevention and control of major non communicable disease: Mental health and substance abuse. [homepage on the Internet] c2014 [cited 2014Jun30]. Available from: http://www.ban.searo.who.int/ en/Section3/Section37/Section96.htm.

120. Firoz AHM, Karim ME, Alam MF, et al. Community based multicentric service oriented research on mental illness with focus on prevalence, medical care, awareness and attitude towards mental illness in Bangladesh. WHO published data, 2003-2005.Bang J Psychiatry 2006; 20 (1):9-32.
121. Islam MM, Ali M, Ferroni P, Underwood P, Alam MF. Prevalence of psychiatric disorders in an urban community in Bangladesh. Gen Hosp Psychiatry 2003;25(5):353-7.

122. Hosain GM, Chatterjee N, Ara N, Islam T. Prevalence, pattern and determinants of mental disorders in rural Bangladesh. Public Health 2007 Jan;121(1):18-24.

123. Genco RJ, Genco FD. Common risk factors in the management of periodontal and associated systemic diseases: the dental setting and interprofessional collaboration. J Evid Based Dent Pract 2014 Jun;14 Suppl:4-16. doi: 10.1016/j.jebdp.2014.03.003. 